\title{
Analysis of Current Employment Situation of Higher Vocational College Graduates
}

\author{
You Ming hui ${ }^{1,}$ a, Wang Yi da ${ }^{2, b^{*}}$ \\ ${ }^{I}$ School of Public Finance and Administration, Harbin University of Commerce \\ ${ }^{2}$ School of Public Finance and Administration, Harbin University of Commerce \\ a2060442350@qq.com \\ b*814249687@qq.com
}

\begin{abstract}
Now in the continuous enrollment expansion in higher vocational colleges, this for the graduates, after graduation to facing the pressure of social competition, higher vocational graduates employment situation is with the national vocational education influence each other, in order to solve the employment problem of graduates, countries began to focus on problems of graduate employment in higher vocational colleges, and take the corresponding measures to solve these problems In this paper, the employment of vocational college graduates to study, and combined with the current situation of graduates to analyze, analysis of the existing problems and put forward relevant countermeasures.
\end{abstract}

Keywords: Higher vocational colleges, graduates, employment analysis

\section{高职院校毕业生就业现状分析}

\author{
尤明慧 $1, a$ 王奕达 $2, b^{*}$
}

\author{
1 哈尔滨商业大学财政与公共管理学院 \\ 2 哈尔滨商业大学财政与公共管理学院 \\ a2060442350@qq.com \\ b*814249687@qq.com
}

\section{摘要}

如今高职院校在进行不断的扩招, 这对于毕业生们来说, 毕业之后要面临着社会竞争所带来的压力, 高职毕业 生的就业状况是与国家职业教育相互影响的, 为了解决毕业生们的就业问题，国家对高职院校毕业生就业问题 开始重点关注，并采取了相应措施去解决这些问题。该文通过对高职院校毕业生的就业问题来进行研究，并结 合目前的毕业生状况来进行分析，分析出所存在的问题并提出相关的对策。

关键词: 高职院校; 毕业生; 就业分析

\section{1.前言}

在最近这几年，毕业生人数越来越多，但是我国 的就业岗位需求数量并没有增多, 甚至很多的事业单 位与政府机关的工作岗位需求量也出现了下降的情 况。与此同时, 总体来说由于大学生毕业人数的越来 越多, 这使得我国整体的就业问题出现了严重的求过 于供的情况, 但是我国很多的地区也出现了就业饱和 的状态, 也有的地区出现了供不应求的状况, 这样的
就业情况出现了很大的矛盾。产生这样问题的原因主 要有两个方面, 一方面是大学生们对自己的未来有着 很高的期望, 更喜欢去一些经济发达的城市与地区去 工作和追求自己想要的生活。另一方面是用人的单位 希望招到可以达到单位标准的人才, 但是毕业生自己 本身就不能够完全的达到用人单位的标准，这样对于 毕业生与用人单位方面就产生了两方都存在缺口的 现状，导致更多的毕业生们找不到的工作，用人单位 也招不到符合要求的员工，从而产生了就业困难，使 
得毕业生们无法顺利找到工作。

\section{2.高职院校毕业生就业基本情况}

\section{1. 相关概念界定}

\subsection{1. 高职院校}

高职院校, 是指经过国家教育部批准设立, 进 行专科职业教育的的普通高等学校 ${ }^{[1]}$ 。这类学校主 要的教育阶段是在高中与技术教育的基础之上而进 行一些专业与技术的教育, 主要目的是为了可以培 养更多的一线工程型以及技术教育型的机构, 是中 国高等教育重要的组成部分。

\subsection{2. 高职毕业生就业}

高职毕业生就业是指, 高职毕业生在院校或者实 习企业中接受一定的课程培训和实践能力培养后, 以 专业知识和操作能力为基础, 提高自己的就业选择能 力, 主要包括: 篮选能力、适应能力和职业目标规划 能力、创新能力和调整能力, 从而争取到一定的或者 自己想要的就业机会 ${ }^{[2]}$ 。高职院校秉持以市场为导向, 以培养学生实践操作能力为宗旨的教学理念, 旨在提 高学生的专业化程度和就业竞争力。

\subsection{3. 高职院校与普通高校的区别}

根据我国目前的教育体制, 高等教育分成了两个 部分, 一是普通高校, 是以培养学术型与复合型人才 作为主要目标; 二是高职院校, 主要是为了可以培养 应用型与技术型的一些人才。而普通的高校主要培养 的重点就是体现在理论上面, 高职院校所培养的重点 主要是在于实践应用这一方面。高职院校的招生范围 一般是以高中毕业生与中专毕业生以及社会人士为 主要群体, 而普通高校的招生范围一般是以高中毕业 生为主要群体 ${ }^{[3]}$ 。现在的社会压力是非常大的, 尤其 是对于毕业找工作这样的问题, 有特别多的大学生毕 业之后找不到工作是很常见的事情, 特别是现在这个 社会非常看重学历, 很多的单位与公司对与工作岗位 的招聘条件都是要求本科及以上的学历, 对于招聘专 科毕业生的单位与公司是非常少的, 所以专科毕业生 与本科毕业生以及硕士毕业生从学历上就有着很大 的距离, 这对于高职院校的毕业生们来说找工作是很 难的。在教学理念上, 普通高校的教学更多重视的是 理论上的知识讲授, 对于动手能力不是很强; 高职院 校所学更多的是理论与实践相结合, 主要强调的是以 就业作为导向, 高职院校毕业生在毕业的时候具有直 接上手的能力, 所以就业市场的竞争力更强。

\section{2. 全国高校毕业生就业情况}

每年的毕业生人数都在上涨, 在 2019 达到了 834 万人, 2020 年的毕业生达到了 874 万人 ${ }^{[4]}$ 。根据麦
可思研究院的就业相关数据统计可看出, 在 2019 年 有 $71.9 \%$ 的毕业生选择直接开始工作，有 $17.4 \%$ 的人 选择在国内或国外进行读研, 考研的有 $4.5 \%$ 人, $1.6 \%$ 的人选择进行创业, 当兵的有 $0.2 \%$ 的人选择, 还剩了 $4.4 \%$ 的人, 他们表示自己毕业之后没有任何的想从事 的方向。对于毕业生们选择的主要行业: 有 $15.9 \%$ 的 人选择从事与教育相关的工作, 有 $8.9 \%$ 的人选择从 事建筑相关的行业, 有 $6.0 \%$ 的人从事了医疗与社会 护理的工作，有 $6.0 \%$ 的人在政府以及公共管理进行 工作，有 $4.6 \%$ 的人从事了文化与体育以及娱乐业的 工作, 运输行业有 $2.4 \%$ 的人等。与此同时, 根据教育 部门对 2021 年全国的毕业生进行统计, 预计毕业生 的人数将会达到最新记录 909 万人, 和之前相比会增 长 35 万人。由于毕业生人数每年都在增多, 这也使 得就业问题也成为了社会上重点讨论的话题。

\section{3. 高职院校毕业生就业情况}

目前, 高职院校毕业的学生就业竞争开始加大, 根据相关的报告当中所统计的, 近几年很多的高职院 校毕业生选择直接工作的人数较少, 很多的人选择专 升本或者不直接工作, 尤其是专升本成为越来越多人 选择。主要是受到了疫情的影响, 有 700 多万的毕业 生们需要找工作, 但是能够从事的岗位越来越少, 很 多人选择专升本, 对于高职院校毕业的学生就业问题 正广泛的被关注。因为疫情的蔓延, 全球的经济在不 断的衰退, 而且两个月在家进行隔离, 使得我国很多 的企业已经面临着倒闭, 不能在给员工提供岗位。这 对刚毕业的学生们来说是一道艰难的门槛。高职院校 是进行培养社会人才的重要场所。但是我国的高职院 校毕业生面对很多的就业困难。

\section{3.高职院校毕业生就业困境}

我国高职院校虽然有了一些发展, 但是对于毕业 生们的就业情况还是不乐观。究其原因主要体现在以 下四个方面。

\section{1. 就业政策实施效果不佳}

高职院校毕业生的就业问题已经逐渐引起国家 以及社会的广泛关注, 国家也越来越重视该群体的就 因为问题 ${ }^{[5]}$ 。国家和多个城市的政府及教育部门对高 职院校的毕业生找工作的问题进行了相关的对策研 究以及政策出台。但是对于政策的实施过程都是很明 显的落后于市场的发展, 从而显得非常僵化。首先, 有些学校给学生进行政策解读的时候, 都是过于表面, 没有更加深入的对适合高职院校毕业生的就业政策 进行解读, 欠缺从多个角度来对就业以及就业政策进 行研究与指导, 这样使得很多的学生对政策不够重视, 对于政策内容也不是很理解, 更加不会运用政策来保 障自身的合法权益。其次, 政策在进行的过程当中, 其内部缺少有效的管理机制, 外部也没有得到有效的 
监督管理，过于形式化，这样很多的政策没有发挥到 应发挥的作用，这样很多的政策很难落实。

\section{2. 人才市场趋于饱和}

我国的高职院校的毕业生人数每年都在增加, 尤 其是 2020 届的毕业生和之前相比多了 40 多万人, 从 而这使得市场上的工作岗位出现了严重紧缺的现象。 并且在目前的国际大环境下, 中国的经济面临着重重 的困难, 国家的经济增长趋势已经由告诉向中高速方 向变化, 中国经济在 2020 年仍然存在着下滑的现象 [6]。与此同时很多的房地产与娱乐以及旅游等行业都 是需要很多的人员进行聚集的工作岗位, 但是因为受 到了新冠肺炎疫情的严重影响让这些行业受到了剧 烈的打击。而且在国家的严厉禁令之下, 这些的行业 不得不把工作岗位数量进行缩减, 或者是处于长期不 开业的状态 ${ }^{[6]}$ 。这样就让很多的高职院校毕业生们在 毕业之后找不到与之相应的工作岗位, 没有了发展的 道路, 这样高职院校毕业生本身就业困难的问题就更 加困难了。除了这一重要原因之外, 还有很多的中小 型企业对于国家的禁令抗压性不强, 从而出现了大量 裁员的情况, 这样的情况进而导致了高职院校毕业生 就业与失业人员再就业并存的现象。这些工作岗位本 身就是应届高职院校的毕业生们首先会选择从事的 工作。对于这样的一边是增加一边是减少的矛盾关系, 使得很多的毕业生在就业的问题上面变得更加困难。

\section{3.企业对学历存在刻板印象}

目前, 我国的高等职业教育在理论指导和办学经 验还不够完善; 再加上人们对于高等职业教育的认识 还不够清楚, 大多数人对于高职院校的办学理念和毕 业生的就业前景还不是十分的了解, 大众片面的认识 对高等职业教育存在偏见, 以至于高职院校的毕业生 在就业选择时没有本科生或者研究生有优势 ${ }^{[7]}$ 。现在 很多的企业对于就业条件存在着很严重的不公平性, 很多的企业喜欢聘用名校的毕业生, 对于硕士研究生 及以上的高学历更是刮目相看, 对于高职院校毕业生 存在着很多的偏见, 很多重要的岗位与核心技术部门 都不接受高职毕业生来从事这门工作, 导致了很多的 高职院校毕业生融入不到企业核心的部门。这对毕业 生个人和家庭以及整个社会都带来了严重的影响, 在 歧视达到了一些程度之后, 就会引起整个社会对于公 平的争议, 这样的情况导致了毕业生找不到工作。但 是每年毕业生数量会不断的增加, 就业的压力已经很 明显的展露出来了, 这样的就业不公平性从而也导致 了企业不能够聘用虽然学历低但是真正有能力的人 才, 人职也不能够有效的得到匹配, 这样的不公平性 问题会对高职院校毕业生群体造成信心上的打击, 也 会引起整个社会就业很慢的现象产生。

\section{4. 盲从专升本热潮}

现在很多的高职毕业生正在盲目跟风去提升自
己的学历。在现在的社会当中, 对人才的评价标准不 在是以文凭来评论能力强不强, 而是根据一个人的知 识水平与个人的能力素养来进行评价的, 但是学历还 是对影响到个人以及职业的发展为主要因素的。有很 多的高职院校毕业生对提升个人学历作为重要的人 生目标, 还有一部分的人是为了短期逃避就业的问题, 没有从自身实际因素考虑而选择专升本, 这样就形成 了盲目跟风的“刷学历”的不良趋势 ${ }^{[8]}$ 。有很多高职院 校的毕业生为了提高学历, 去参加辅导课程, 补习专 业知识, 从而来达到延缓就业的问题, 但是这样会给 部分家庭带来严重的经济负担, 这与满足经济发展的 需求所相反。

\section{4.缓解高职院校毕业生就业困境的对策}

\section{1. 完善高职学生就业服务体系}

首先, 政府要加大扶持力度对高职院校, 还要进 行与时俱进的改革对高等职业教育的制度, 对于稳定 的就业岗位与开发新的就业岗位还有对找不到工作 的高职院校的毕业生这些上面做一些功夫, 从而来促 进就业的措施。要增加多个工作岗位, 并对新的工作 岗位进行宣传, 从而来打破传统的行业与工作岗位的 限制, 来让更多的毕业生进行寻找新兴领域的一些就 业机会。其次，对于一些僵化的就业政策要进行一定 改进的措施, 这样可以更好的完善职高毕业生的就业 政策, 要对高职院校毕业生就业问题的对策尽快进行 实施。政府要推出对各企业招聘高职院校毕业生的相 关鼓励政策，并对这些招聘高职院校的企业提供便利 的条件。与此同时, 还要完善与就业政策相关联的法 律法规, 完善与人才保护有关联的一些劳动法规, 在 法规上面为高职院校的毕业生们提供出良好的就业 环境。

\section{2.多领域多渠道解决就业问题}

虽然在 2020 年很多的高职院校毕业生面临着找 不到工作的问题，但是国家推出了相关的对策。现在 很多的学校进行了扩招研究生, 目前在 2020 年已经 扩招了 18.9 万人; 同时, 专升本也进行了扩招, 一共 扩招 32.3 万人。这样的政策措施对于想要高学历的 毕业生群体来说是很好的消息, 还可以继续参加学习, 从而为以后想要找到理想的工作奠定了基础并且增 加了更多的优势。与此同时, 还对部分就业的岗位进 行了一些相关的措施实施, 对于特岗教师的工作岗位 也扩招了 5000 人, 很多的地区也鼓励大学生参军入 伍，同时还鼓励了很多的企业进行线上招聘的活动。 以及各地区的当地政府以及教育部门应该多去考察 当地的实际情况, 并且要观察好当地社区的管理以及 公共卫生等领域是否缺少相关的人才, 并且鼓励高职 院校的毕业生群体和失业的毕业生群体从基层工作 开始做起, 从而进行一些锻炼。 


\section{3. 改革高职教育体系}

我国的高等职业教育体制在不断的深化，高等职 业教育体系也在不断完善。部分企业在进行面试的时 候, 对于工作岗位的分配与职位的晋升还有薪资上面 都对本科生与专科生都进行了明显的区分, 有特别多 的事业单位都对专科毕业的学生存在着偏见, 对于学 历的这一硬性门槛让高职院校的毕业生就业开始变 得十分困难。教育部门需要对高等职业教育进行一些 资源投入并把教育资源进行合理的分配，从而得到高 等职业教育的高质量发展, 以便于高等职业教育的改 革和良好快速的发展, 慢慢的让大众对高职院校的毕 业生群体改变之前的偏见, 从而来让高职院校的毕业 生获得平等的就业机会与尊重。高职院校要加快教育 改革, 在全国范围内推进职业培训以及高职院校毕业 生群体专业技能的认证工作, 适时调整技术人才培养 策略。

\section{4.耦合就业观念和个人能力}

在我国社会快速的发展过程当中, 存在着很多 的线上培训方式, 很多的老师也利用微信公众号以 及各种网络的平台来进行培养学生的就业能力以及 就业的价值观等, 但是在这同时还要适当的进行宣 传“就业促进法”与“劳动法”等一些就业相关政策内 容, 这样不仅可以让更多的高职院校的毕业生能够 顺利的就业, 还可以为高职院校毕业生群体打好坚 实的就业基础。这样对于毕业生群体来说, 就业的 能力本身就是很关键的一点, 这些主要是与一个人 的自身性格与习惯以及个人态度与认识程度相关联 的。高职院校的教师在进行培养学生的过程当中应 该充分的发挥出自身的教育能力, 并且可以利用一 些线上的教学指导方式来对学生就业进行培训, 从 而来提高高职院校学生的学习能力和接受能力以及 就业能力。就业的整体是学生, 本身就是需要接受 培养与教育的, 所以要充分的发挥出对学习的热 情, 从而来提高就业培训的整体效果。

\section{5.结论}

在进行扩招的背景之下, 为了可以改变高职院校 毕业生们找工作困难的这一情况, 首先, 是高职院校 应该尊从政府领导和各方面的意见, 以及对软件与硬 件的建设进行完善, 要提升学生的服务能力与师资力 量, 还要完善好有关就业的指导, 对高职院校教师团 队进行建设。其次, 对高职院校应该对就业加强, 并 且还应该加强对就业创业信息的收集, 实时的关注学 生所要面临的创业与就业过程中所面临的的问题, 对 学生所面对的困难提供一些帮助, 分析并找出就业困 难的原因, 并且要建立就业实践的平台。最后, 还要 加强学校与企业之间的合作, 使得企业充分了解高职 院校毕业生的能力, 并且能够提升学生的专业能力和 素质等一些方面, 从而来促进学校的教学改革, 并且 还要完善教学理念和提高办学的水平, 要更好的提升
对高职院校毕业生群体的就业水平与能力, 解决好高 职院校毕业生在就业过程所面临的困难与问题, 实现 高职院校毕业生充分就业。

\section{REFERENCES}

[1] Xu Bingbing. Research on Students' Evaluation System of Teaching in Universities in China [D]. Qingdao University, 2018.

[2] Zhu Daoping. Teaching Research on Employment and Entrepreneurship Guidance for College Students in Higher Vocational Colleges - A Case Study of Lijiang Normal College [J]. Journal of Hetian Normal College,2017,36(06):34-37.

[3] Liu Feng. Research on Teachers' Motivation in Higher Vocational and Technical Colleges [D]. Shandong Normal University,2006.

[4] Mettam, G.R., Adams, L.B. (2009) How to prepare an electronic version of your article. In: Jones, B.S., Smith, R.Z. (Eds.), Introduction to the Electronic Age. E-Publishing Inc., New York. pp. 281-304.

[5] Li Peng. Investigation on the Employment of Vocational College Graduates [D]. Hebei Normal University,2020.

[6] Zhang Yang. Research on the Employment Dilemma and Countermeasures of College Students in Higher Vocational Colleges under the New Challenges $[\mathrm{J}]$. Guangxi Quality Supervision Herald,2021(04):68-69.

[7] Peng Jun. Research on the Strategy of Higher Vocational Students' Employ ability and Competency Enhancement [J]. Science and Technology wind,2019(35):223.

[8] Zuo Fangxia. A Probe into the Employment Dilemma and Causes of Higher Vocational College Graduates [J]. Journal of Yuzhang Normal University,2020,35(05):117-120. 